\title{
STRATEGI PROMOSI PARIWISATA PADA KAWASAN WISATA MANGROVE PENDOPO TERITIP, KELURAHAN TERITIP, KECAMATAN BALIKPAPAN UTARA
}

\section{Boby Mugi Pratama1*, Hendy Indrawan Sunardi' ${ }^{2}$, Siti Indreani ${ }^{3}$, Dian Puspitasari ${ }^{4}$, Putu Septa5 ${ }^{5}$ Rut Nauli Hosana ${ }^{6}$, Shoffi Akmalunnisaa ${ }^{7}$, Richard Chandra Tjiang8}

1,2,3,4,5,6,7,8 Institut Teknologi Kalimantan, Balikpapan, Indonesia

*Penulis Koresponsensi, email: bmpratama@lecturer.itk.ac.id

\begin{abstract}
Improving the community's economy and national energy security are the main focus in the utilization of regional potential in the city of Balikpapan. As a form of contribution from educational institutions in this regard, Kalimantan Institute of Technology (ITK) held a program to improve the quality of natural resources and human resources in Kelurahan Teritip, Balikpapan City, which was stated in Program Mahasiswa Mengabdi Desa (PMMD). The problem faced by the Mangrove Pendopo Teritip in Kelurahan Teritip is the unavailability of adequate markers that indicate if at that location there is a mangrove tourism spot, thus making the Mangrove Pendopo Teritip unknown to visitors who are not from the surrounding area. The solution that has been implemented is to use digital promotions using advertisements on online platforms such as Instagram with the destination of Mangrove Pendopo Teritip tourism in Kelurahan Teritip, which can be known by wider community, especially the people of Balikpapan. Then also made a direction marker that leads to the Mangrove Pendopo Teritip tourism with the aim of being able to help and make it easier for people from outside the area to find the tourist location of this Mangrove Pendopo Teritip. In addition, a program for making both thematic maps of tourist sites and mangrove education information boards was also carried out so that they could serve as informative messages for tourists. The program was implemented in a period of approximately 12 weeks.
\end{abstract}

Keywords: tourism, mangrove, promotion

Abstrak. Peningkatan ekonomi masyarakat dan ketahanan energi nasional menjadi fokus utama dalam pemanfaatan potensi daerah di Kota Balikpapan. Sebagai bentuk kontribusi institusi pendidikan dalam hal tersebut, maka Institut Teknologi Kalimantan (ITK) mengadakan program untuk meningkatkan kualitas sumber daya alam dan sumber daya manusia di Kelurahan Teritip Kota Balikpapan yang tertuang dalam Program Mahasiswa Mengabdi Desa (PMMD). Permasalahan yang dihadapi oleh wisata Mangrove Pendopo Teritip di Kelurahan Teritip berupa tidak tersedianya promosi yang memadai yang menunjukan jika pada lokasi tersebut terdapat wisata Mangrove Pendopo Teritip, sehingga menjadikan wisata Mangrove Pendopo Teritip tidak diketahui lokasinya oleh pengunjung yang bukan berasal dari daerah sekitar. Solusi yang telah dlaksanakan adalah menggunakan promosi digital menggunakan iklan di dalam platform online seperti Instagram dengan tujuan wisata Mangrove Pendopo Teritip di Kelurahan Teritip ini dapat diketahui dan dikenal oleh masyarakat secara luas khususnya masyarakat Balikpapan. Kemudian dilakukan pula pembuatan penanda arah yang mengarah ke wisata Mangrove Pendopo Teritip dengan tujuan dapat membantu dan memudahkan masyarakat dari luar daerah tersebut untuk mencari lokasi wisata Mangrove Pendopo Teritip ini. Selain itu dilaksanakan juga program pengadaan peta tematik lokasi wisata dan papan informasi edukasi mangrove sehingga dapat menjadi pesan informatif untuk wisatawan. Program tersebut terlaksana dalam kurun waktu kurang lebih 12 pekan.

Kata Kunci: wisata, mangrove, promosi

How to Cite: Pratama, B.M., Sunardi, H. I., Indreani, S., Puspitasari, D., Septa, P., Hosana, R. N., Akmalunnisaa, S., \& Tjiang, R. C. (2022). Strategi Promosi Pariwisata Pada Kawasan Wisata Mangrove Pendopo Teritip, Kelurahan Teritip, Kecamatan Balikpapan Utara. Mitra Mahajana: Jurnal Pengabdian Masyarakat, 3(1), 12-17. doi: https://doi.org/10.37478/mahajana.v3i1.1303

\section{PENDAHULUAN}

Peningkatan ekonomi masyarakat dapat diwujudkan dengan mengoptimalkan potensi sumber daya alam yang ada serta dikolaborasikan dengan peningkatan kualitas sumber daya manusia pada suatu daerah. Dengan memanfaatkan potensi daerah setempat, baik dari segi sumber daya alam, sumber daya manusia maupun sumber daya buatan lainnya, maka akan sangat memungkinkan terjadi perkembangan ekonomi masyarakat dengan ketahanan energi yang kuat di Indonesia, dan khususnya di Kota Balikpapan. 
Wilayah pesisir dan masyarakat di sekitarnya yang merupakan bagian dari sumber daya alam, sumber daya manusia, dan budaya setempat. Wilayah pesisir laut Kota Balikpapan masih menyimpan potensi sumber daya. Hal ini terlihat dari fungsi utama Kota Balikpapan yang tertuang di dalam Peraturan Pemerintah Nomor 26 Tahun 2008 tentang Rencana Tata Ruang Wilayah Nasional dimana salah satu fungsi utama Kota Balikpapan ialah sebagai Pusat Pelayanan Jasa Pariwisata. Oleh karena itu masyarakat pesisir harus diberdayakan sesuai dengan kondisi dan potensinya masing-masing, salah satunya di bidang pariwisata.

Kelurahan Teritip merupakan salah satu kelurahan di Kecamatan Balikpapan Timur Kota Balikpapan. Walaupun bukan sebagai potensi wisata prioritas (Putri dkk., 2017), Kelurahan Teritip saat ini sedang dikembangkan untuk menjadi salah satu destinasi wisata alam andalan dalam Rencana Tata Ruang Wilayah Kota Balikpapan Tahun 2012-2032. Selain terkenal dengan wisata penangkaran buaya nya, Teritip juga memiliki kawasan wisata pesisir berupa hutan mangrove yang merupakan pelindung pantai dari abrasi laut (Balikpapan Pos, 2017). Hutan mangrove ini berfungsi sebagai penahan abrasi pantai, penahan badai dan angin, serta sebagai tempat hidup biota laut dan berbagai satwa lain (Dewi, 2011). Selain itu, hutan Mangrove ini juga dijadikan tempat wisata sebagaimana ditunjukkan dalam Gambar 1.

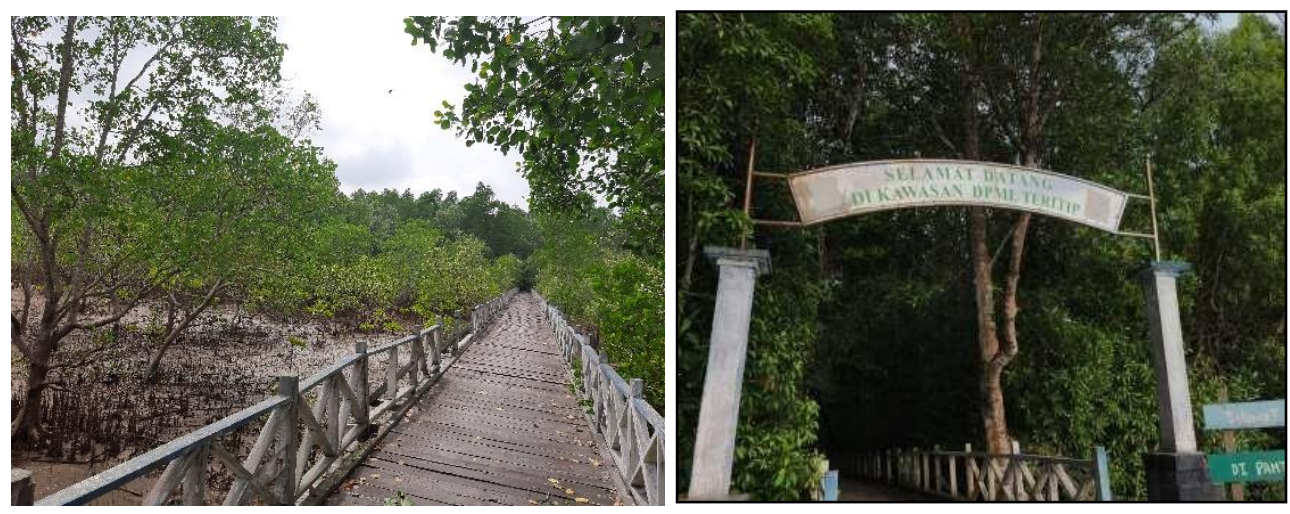

Gambar 1. Kondisi wisata Mangrove Pendopo Teritip

Wisata Mangrove sangat potensial untuk menjadi sumber ekowisata bagi masyarakat pesisir Kelurahan Teritip (Junus dkk., 2019). Namun, terjadi berbagai permasalahan yang membuat wisata Mangrove Pendopo Teritip ini belum banyak berkembang. Permasalahan yang dihadapi oleh wisata Mangrove Pendopo Teritip di Kelurahan Teritip berdasarkan hasil pengatamatan yang dilakukan di lapangan antara lain berupa tidak tersedianya promosi yang memadai yang menunjukan jika pada lokasi tersebut terdapat wisata Mangrove Pendopo Teritip, sehingga menjadikan wisata Mangrove Pendopo Teritip tidak diketahui lokasinya oleh pengunjung yang bukan berasal dari daerah sekitar. Wisata Mangrove Pendopo Teritip ini juga masih kurang dengan pengembangan potensi yang ada seperti ekowisata maupun wisata edukasi.

\section{METODE PELAKSANAAN}

Metode pelaksanaan yang dilakukan dalam Program Mahasiswa Mengabdi Desa (PMMD) yang diselenggarakan pada wisata Mangrove Pendopo Teritip Kelurahan Teritip guna mengatasi permasalahan yang telah disebutkan adalah sebagai berikut:

1. Terkait dengan permasalahan dimana wisata Mangrove Pendopo Teritip ini masih belum dikenal masyarakat luas, sehingga berakibat pada wisatawan yang datang hanya terbatas dari masyarakat yang bertempat tinggal di sekitar wisata mangrove tersebut, maka solusi yang diberikan adalah dengan melakukan promosi digital. Wisata Mangrove Pendopo Teritip dipromosikan dan diperkenalkan menggunakan postingan berupa gambar dan video di platform daring seperti Instagram dan Facebook. Promosi dilakukan pada akun media sosial yang telah terkemuka bagi masyarakat Balikpapan. Hal ini bertujuan agar 
wisata Mangrove Pendopo Teritip di Kelurahan Teritip ini dapat diketahui dan dikenal oleh masyarakat secara luas khususnya masyarakat Balikpapan.

2. Terkait dengan tidak diketahuinya wisata Mangrove Pendopo Teritip ini oleh pengunjung yang bukan berasal dari daerah sekitar, maka dibuatlah fasilitas penanda arah di sekitar lokasi wisata untuk mengarahkan wisatawan yang hendak berwisata ke Mangrove Pendopo Teritip. Fasilitas yang lengkap adalah faktor utama masyarakat Balikpapan dalam menentukan destinasi wisata (Putra dkk., 2016)

3. Guna memanfaatkan wisata mangrove sebagai wisata edukasi, dibuat pula papan informasi mengenai nama mangrove, jenis mangrove, manfaat mangrove dan segala informasi terkait mangrove yang disertai dengan gambar. Hal ini juga bertujuan untuk memberikan edukasi terhadap pengunjung yang datang ke wisata Mangrove Pendopo Teritip.

4. Guna mempromosikan pariwisata di Kelurahan Teritip, dibuat pula peta tematik berupa denah wisata yang ada di Kelurahan Teritip. Hal ini berangkat dari permintaan pihak Kelurahan Teritip PMMD di Kelurahan Teritip. Tahap pengerjaannya dimulai dengan melakukan survei lapangan terlebih dahulu. Kemudian dilanjutkan dengan mendata wisata-wisata apa saja yang ada di Kelurahan Teritip. Terakhir, dibuatlah peta tematik berupa infografis lokasi wisata di Kelurahan Teritip.

\section{HASIL DAN PEMBAHASAN}

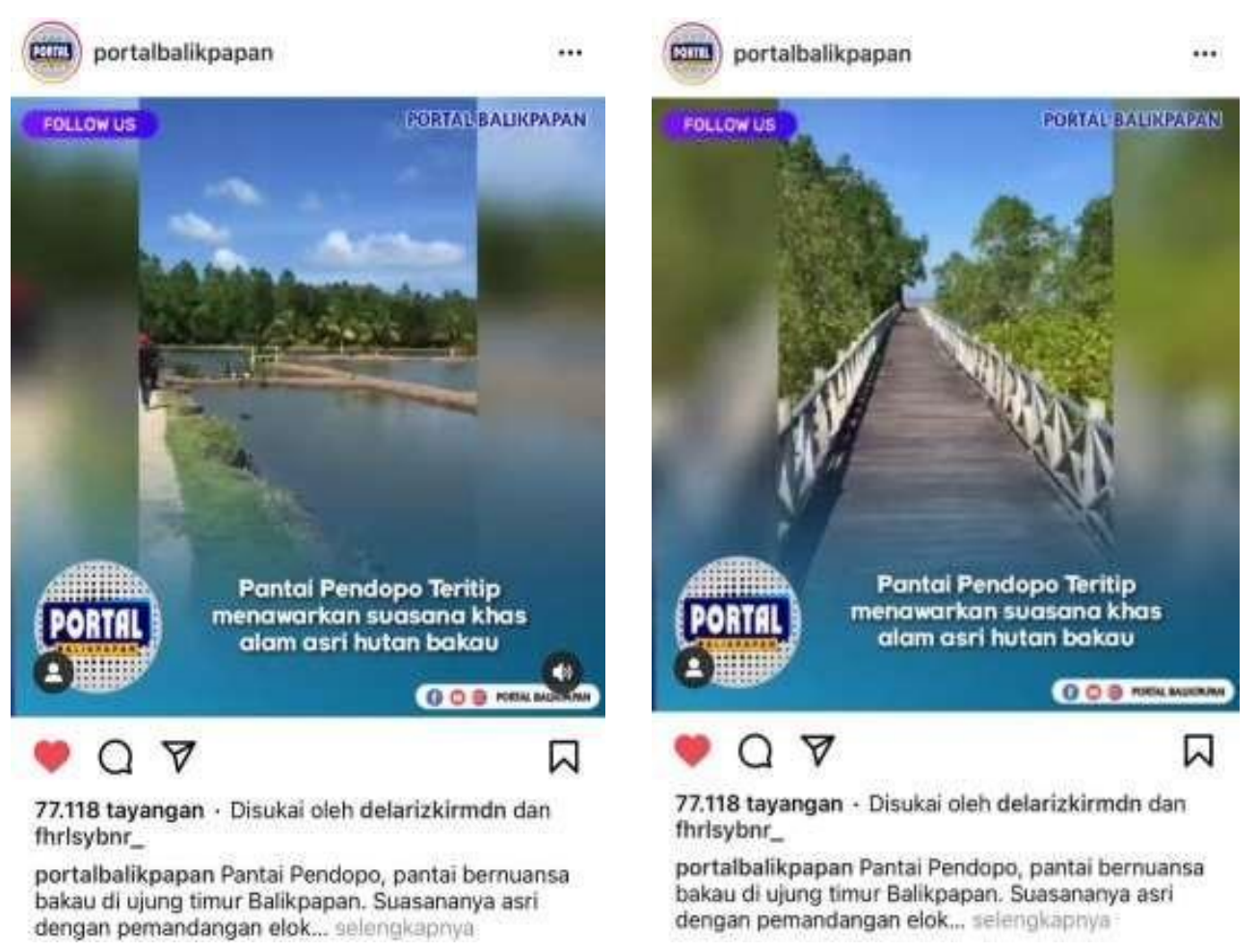

Gambar 2. Publikasi wisata Mangrove Pendopo Teritip

Promosi digital untuk memperkenalkan wisata Mangrove Pendopo Teritip dilakukan dengan menampilkan dokumentasi menarik dari lokasi wisata ini. Promosi digital tersebut diperlihatkan sebagaimana pada Gambar 2. Promosi yang dilakukan pada media sosial Instagram Portal Balikpapan @portalbalikpapan menghasilkan 77.118 tayangan hingga saat artikel ini ditulis. Akun tersebut dipilih karena hingga saat artikel ini ditulis, @portalbalikpapan memiliki jumlah pengikut hingga sekitar 291.000 pengikut yang mana Sebagian besar adalah masyarakat Balikpapan. 
Selain diperkenalkan menggunakan promosi digital, dibuat pula penanda arah yang mengarah ke wisata Mangrove Pendopo Teritip. Hal ini dilakukan untuk membantu dan memudahkan wisatawan dari luar daerah tersebut untuk mencari lokasi wisata Mangrove Pendopo Teritip. Penanda arah menuju ke lokasi wisata ditunjukkan sebagaimana pada Gambar 3. Dengan demikian, diharapkan wisatawan yang pertama kali berkunjung karena merespon promosi digital yang diberikan sebelumnya dapat dengan mudah menemukan lokasi wisata ini.

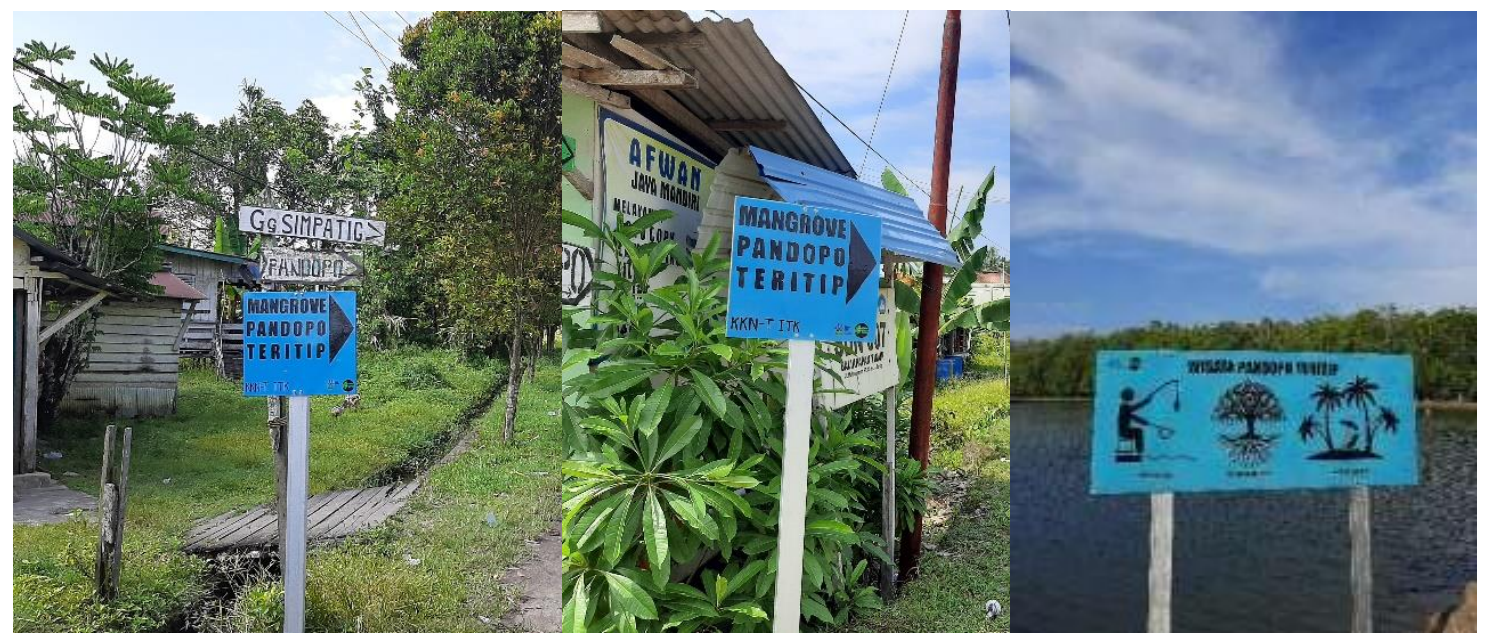

Gambar 3. Penanda arah menuju lokasi wisata Mangrove Pendopo Teritip

Wisata Mangrove Pendopo Teritip juga dimanfaatkan sebagai sarana edukasi wisatawan untuk mengenali mangrove dan memahami pentingnya keberadaan mangrove di wilayah pesisir. Untuk itu dibuatlah papan informasi mengenai nama, jenis, manfaat dan segala informasi terkait mangrove disertai dengan gambar dengan tujuan memberikan edukasi terhadap pengunjung yang datang ke wisata Mangrove Pendopo Teritip. Papan informasi ini ditunjukkan sebagaimana pada Gambar 3.
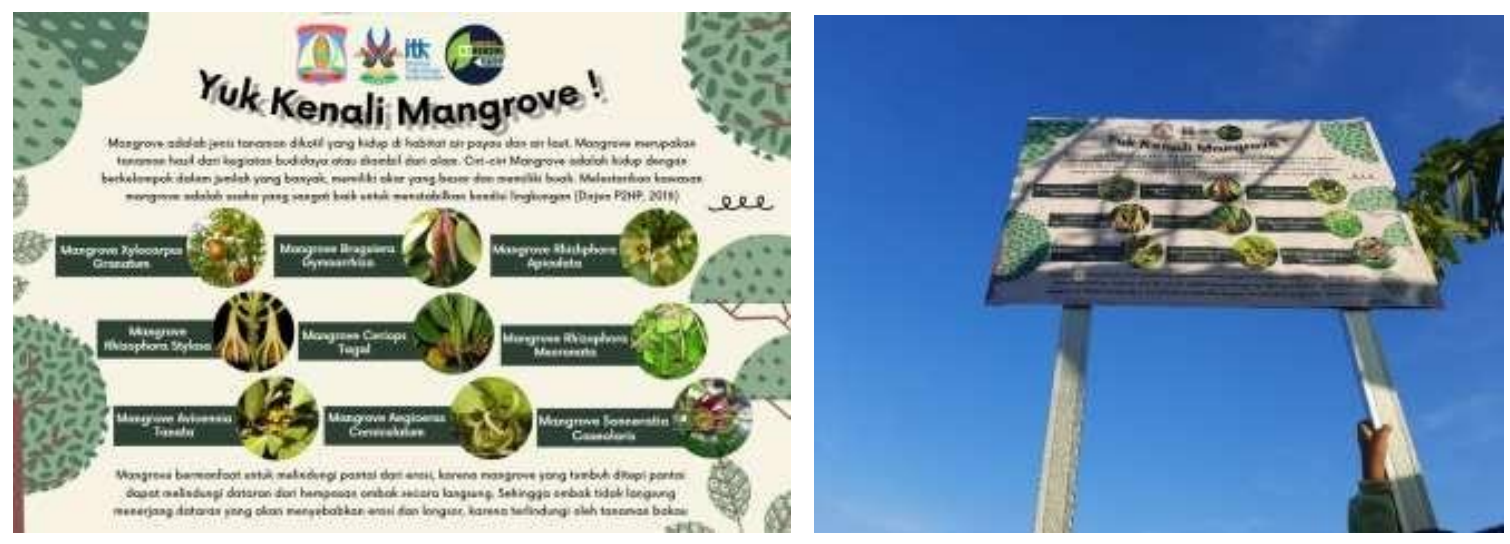

Gambar 4. Papan informasi edukasi mangrove

Selanjutnya pembuatan peta tematik berisikan lokasi wisata yang ada di Kelurahan Teritip menghasilkan Peta Denah Wisata yang tunjukkan sebagaimana pada Gambar 5. Peta dibuat setelah dilakukan survei lapangan terlebih dahulu guna mendata wisata-wisata apa saja yang ada di Kelurahan Teritip kemudian di buah peta nya secara infografis. Peta di cetak dengan ukuran 20R berbingkai, yang kemudian di serahkan kepada pihak Kelurahan Teritip. Penyerahan ini sekaligus menjadi kegiatan penutup PPMD di kawasan wisata Mangrove Pendopo Teritip. 


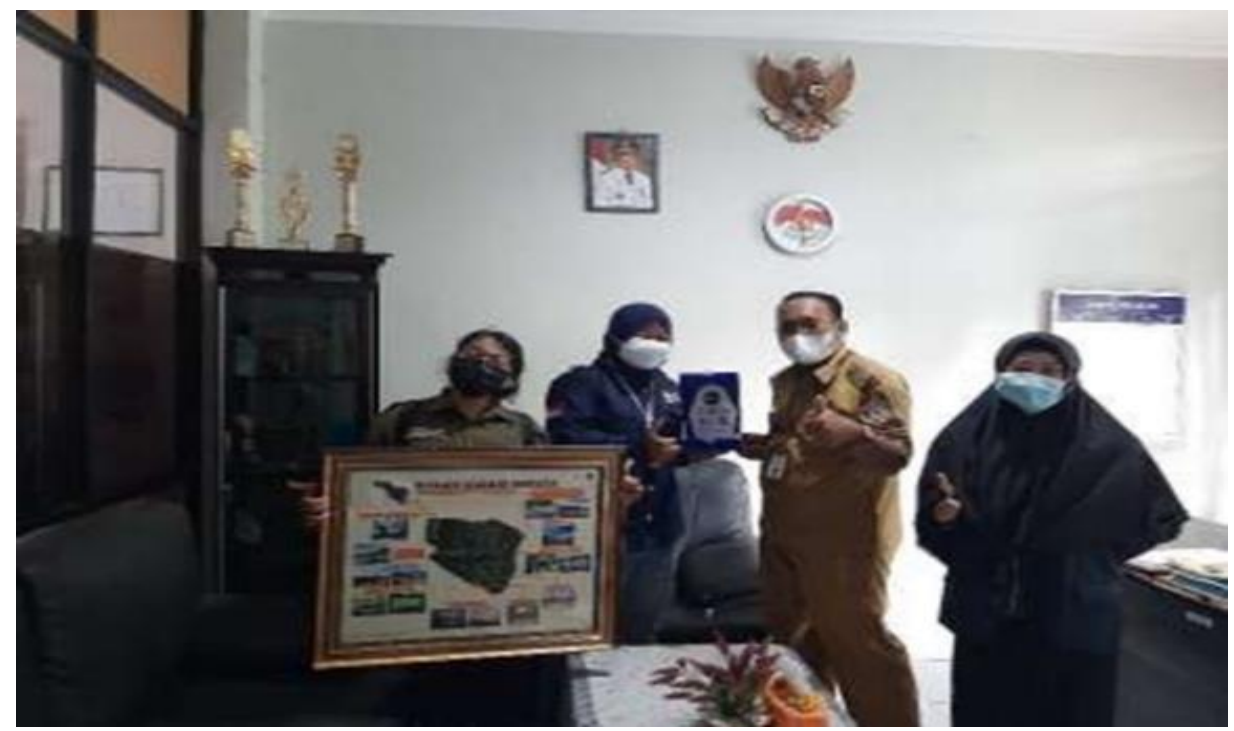

Gambar 5. Penyerahan peta denah wisata kepada Kelurahan Teritip

\section{SIMPULAN DAN TINDAK LANJUT}

Telah dilaksanakan berbagai program selama 12 pekan guna mempromosikan dan memajukan wisata Mangrove Pendopo Teritip. Program yang dilakukan terdiri atas promosi digital di media sosial dan pembuatan media informatif di lokasi dan sekitar tempat wisata. Kegiatan ini diharapkan dapat meningkatkan jumlah wisatawan yang mengetahui dan berkunjung ke lokasi wisata Mangrove Pendopo Teritip.

Untuk diketahui bersama, program terkait promosi saja tidak cukup untuk meningkatkan nilai jual wisata mangrove di Kelurahan Teritip. Saran untuk berbagai pihak yang terkait agar dapat terjalin kerjasama dengan pemerintah ataupun swasta untuk dapat meningkatkan kualitas pelayanan dan perawatan kawasan mangrove dimana hal ini membutuhkan dana yang tidak sedikit. Fasilitas yang lengkap adalah faktor utama masyarakat Balikpapan dalam menentukan destinasi wisata. Untuk itu berbagai perbaikan dibutuhkan terutama dibagian jembatan yang sudah mulai rusak.

Selain dari segi fasilitas, kelestarian mangrove juga perlu dijaga. Hal ini dapat dilakukan dengan cara melakukan segala upaya agar wisatawan tidak membuang sampah sembarangan ataupun melakukan hal lain yang dapat merusak ekosistem mangrove.

\section{DAFTAR PUSTAKA}

Balikpapan Pos. (2017). Teritip Punya Objek Wisata Mangrove. Diakses 1 Oktober 2021 pada https://balikpapan.prokal.co/read/news/210545-teritip-punya-objek-wisata-mangrove

Dewi, I. P. (2011). Perubahan Garis Pantai dari Pantai Teritip Balikpapan sampai Pantai Ambarawang Kutai Kertanegara Kalimantan Timur. Tesis. Institut Pertanian Bogor, Bogor. Diakses pada https://repository.ipb.ac.id/handle/123456789/51562

Junus, N. I., Suyatna, H. I., \& Sidik, A. S. (2019). PROSPEK DAN STRATEGI PENGEMBANGAN EKOWISATA MANGROVE DI KELURAHAN TERITIP BALIKPAPAN. AGRIFOR, 18(2), 275. https://doi.org/10.31293/af.v18i2.4228

Presiden RI. (2008). Peraturan Pemerintah RI Nomor 26 Tahun 2008 tentang Rencana Tata Ruang Wilayah Nasional. Presiden Republik Indonesia. Diakses 1 Oktober 2021 pada https://peraturan.bpk.go.id/Home/Download/37104/PP\%2026\%20Tahun\%202008.p $\mathrm{df}$ 
Putra, R. T., Putri, Y. R., \& Malau, R. M. U. (2016). Strategi City Branding Kota Balikpapan Dalam Meningkatkan Minat Wisatawan (studi Pada Dinas Pemuda Olahraga Kebudayaan Dan Pariwisata Kota Balikpapan). eProceedings of Management, 3(3).

Putri, K. A., Dewanti, A. N., \& Muntaha, M. (2017). Penentuan Potensi Wisata Prioritas melalui Pendekatan Community-Based Tourism di Desa Wisata Teritip Kota Balikpapan. Journal of Regional and Rural Development Planning (Jurnal Perencanaan Pembangunan Wilayah Dan Perdesaan), 1(3), 298-306. https://doi.org/10.29244/jp2wd.2017.1.3.298-306

Walikota Balikpapan. (2021). Peraturan Daerah Kota Balikpapan Nomor 12 Tahun 2012 tentang Rencana Tata Ruang Wilayah Kota Balikpapan Tahun 2012-2032. Pemerintah Kota Balikpapan. Diakses 2021 Oktober 2021 pada http://web.balikpapan.go.id/uploaded/ProgramKerja/RTRW_Kota_Balikpapan_2012.pd $\mathrm{f}$ 